\title{
Natural transmission of Leishmania infantum through experimentally infected Phlebotomus perniciosus highlights the virulence of Leishmania parasites circulating in the human visceral leishmaniasis outbreak in Madrid, Spain
}

\author{
Inés Martín-Martín ${ }^{1}$, Maribel Jiménez ${ }^{1 *}$, Estela González ${ }^{1}$, César Eguiluz $^{2 \wedge}$ and Ricardo Molina ${ }^{1 *}$
}

\begin{abstract}
A human leishmaniasis outbreak is occurring in the Madrid region, Spain, with the parasite and vector involved being Leishmania infantum and Phlebotomus perniciosus respectively. The aim of this study was to investigate the virulence of $L$. infantum isolates from the focus using a natural transmission model. Hamsters were infected by intraperitoneal inoculation (IP) or by bites of sand flies experimentally infected with $L$. infantum isolates obtained from P. perniciosus collected in the outbreak area (IPER/ES/2012/BOS1FL1 and IPER/ES/2012/POL2FL6) and a well characterized L. infantum strain JPCM5 (MCAN/ES/98/LLM-877). Hamster infections were monitored by clinical examination, serology, culture, parasite burden, Giemsa-stained imprints, PCR, histopathology and xenodiagnostic studies. Establishment of infection of L. infantum was achieved with the JPCM5 strain and outbreak isolates by both P. perniciosus infective bites or IP route. However, high virulence of BOS1FL1 and POL2FL6 isolates was highlighted by the clinical outcome of disease, high parasite detection in spleen and liver, high parasitic loads and positivity of Leishmania serology. Transmission by bite of POL2FL6 infected flies generated a slower progression of clinical disease than IP infection, but both groups were infective to $P$. perniciosus by xenodiagnosis at 2 months post-infection. Conversely, hamsters inoculated with JPCM5 were not infective to sand flies. Histopathology studies confirmed the wide spread of POL2FL6 parasites to several organs. A visceral leishmaniasis model that mimics the natural transmission in nature allowed us to highlight the high virulence of isolates that are circulating in the focus. These findings contribute to a better understanding of the outbreak epidemiology.
\end{abstract}

\section{Introduction}

Visceral leishmaniasis (VL) is considered one of the most devastating neglected diseases accounting worldwide with 58000 cases per year [1]. The causative agent in the Mediterranean Basin is Leishmania infantum being promastigote forms transmitted to the vertebrate host by the

\footnotetext{
*Correspondence: mjimenez@isciii.es; rmolina@isciii.es

$\wedge$ Deceased

1 Unidad de Entomología Médica, Servicio de Parasitología, Centro

Nacional de Microbiología, Instituto de Salud Carlos III, Ctra.

Majadahonda-Pozuelo s/n, Majadahonda, 28220 Madrid, Spain

Full list of author information is available at the end of the article
}

bite of infected sand flies [2]. Animal models are essential to test new treatments and vaccines to fight this disease. In cutaneous leishmaniasis $(\mathrm{CL})$, rodents have been widely used to reproduce skin lesions [3]. However, in the case of $\mathrm{VL}$, mice do not completely reflect the human development of the disease and even infection in susceptible mice strains to L. infantum may become chronic. Therefore, the hamster is considered a better model to reproduce the clinicopathological features of human VL [3] and has been widely used for immunological studies [4-7]. A proper and reliable animal model should mimic the natural transmission conditions with special emphasis on dose, pathogen stage delivered, co-administered 
molecules and administration route [8]. In the case of Leishmania, transmission occurs when an infected sand fly takes or attempts to take a blood meal from the vertebrate host. This is a complex process in which sand flies, as telmophagic insects, need to lacerate tissues and create a hemorrhagic pool from where they ingest blood.

Arthropod-borne pathogens have adapted their routes of entry into the vertebrate hosts. The administration route determines the first encounter of the parasite with the immune system, which can drive either to a susceptible or protective response and is highly involved in the outcome of cutaneous or visceral disease. Therefore, infections initiated by parasites directly delivered into the bloodstream do not reproduce the immunological responses that take place under natural conditions [8].

The required number of parasites to initiate a Leishmania infection seems to depend on the Leishmania species or even the strain. Natural infectious doses are much lower than the experimental infectious doses used for parasite infection in the laboratory where $10^{8}$ or $10^{7}$ promastigotes are usually inoculated. The average of $L$. infantum parasites ejected from Lutzomyia longipalpis was recently established at 1000 promastigotes by Rogers et al., who analyzed it with feeding infected sand flies through chick skin [9]. Natural transmission models have provided information regarding individual variability. Concretely, the number of inoculated parasites in the Leishmania major-Phlebotomus duboscqi combination follow a bimodal distribution, corresponding to a low dose of less than 600 parasites, and a high dose between 1000 and 100000 parasites [10]. Other authors have offered similar results and demonstrated that sand flies infected with a dermotropic strain inoculate a greater number of parasites than sand flies infected with a viscerotropic strain [11]. Moreover, Leishmania ejected doses do not seem to depend on the nature of the vertebrate hosts [12].

Leishmania parasites are inoculated into the dermis of the host along with very active immunomodulatory substances such as saliva and promastigote secretory gel (PSG). Sand fly saliva counteracts vertebrate hemostatic and immune responses to ensure blood feeding success and has been directly involved in the establishment of infection $[13,14]$. On the contrary, PSG blocks the anterior part of the midgut and stomodeal valve. As a consequence, metacyclic promastigotes are regurgitated during blood feeding, resulting in an improved transmission efficacy [15].

In leishmaniasis animal models, cultured promastigotes are normally used as the source of infective material which is not the appropriate pathogen stage delivered in nature. Among several promastigote forms present in the midgut of sand flies only metacyclic stages are known to be resistant to vertebrate complement destruction and therefore able to initiate infection [16]. This drawback is usually overcome by working with stationary phase cultures which are enriched in metacyclic forms or isolation of metacyclic promastigotes by lectin agglutination [17].

Reports of laboratory transmission of Leishmania spp. by experimentally infected sand flies are still scarce. Success of natural transmission has been achieved mainly in CL models [14, 18-25]. Although VL models initiated through infected sand fly bites are not easy to reproduce, several studies have been conducted using mice, hamsters, rats or dogs as vertebrate hosts demonstrating succesful transmission [11, 12] or both succesful transmission and animal infection follow-up [26-33].

Human leishmaniasis due to L. infantum is endemic in Spain. However, there has been an unusual rise of human leishmaniasis cases in an urban area of the south-western Madrid region since 2010 [34]. A total of 616 human cases have been reported from the beginning of the outbreak to February 2015, corresponding to 38\% VL. The large number of human cases has led to an increased incidence from 2.44/100 000 inhabitants in 2009 to 49.0/100 000 inhabitants in 2014 in Fuenlabrada, the most affected municipality (Community of Madrid, personal communication). On the contrary, canine leishmaniasis prevalence in the focus is lower than the average in the Madrid region [35, 36] and two wild animals - the hare and the rabbit- have shown to play a role as reservoirs [37, 38].

In this work, our aim was to study the virulence of $L$. infantum isolates that are circulating in the human leishmaniasis outbreak of Madrid using a natural transmission model of VL in the hamster.

\section{Materials and methods \\ Parasites}

Leishmania infantum parasites used in this study included two isolates from Phlebotomus perniciosus collected in the field during the entomological survey carried out in the transmission season of 2012 in the human leishmaniasis outbreak area in Madrid (IPER/ES/2012/ BOS1FL1 and IPER/ES/2012/POL2FL6, referred to as BOS1FL1 and POL2FL6, respectively). Simultaneously, the well characterized L. infantum strain JPCM5 was used as a control. JPCM5 is a clone obtained from the JPC strain isolated from a naturally infected dog (MCAN/ES/98/LLM-877) and maintained at the WHO Collaborating Center for Leishmaniasis, Parasitology Department, Instituto de Salud Carlos III (ISCIII), Madrid, Spain. This clone was used for $L$. infantum genome sequencing [39] and has been widely utilized for experimental challenge [40].

All parasites were passaged through hamsters before the experiments. Promastigotes were cultured at $27^{\circ} \mathrm{C}$ in 
NNN and RPMI supplemented with 10\% inactivated fetal calf serum (FCS, Lonza, Basilea) and a mixture of penicillin and streptomycin $(10000 \mathrm{U} / \mathrm{mL}$, Lonza, Basilea).

\section{Experimental infection of sand flies}

A Phlebotomus perniciosus colony originally established with specimens collected in an endemic area of leishmaniasis in Madrid, Spain [41] maintained at $27^{\circ} \mathrm{C}$ and 17:7 light-darkness photo-period at the insectary of the Medical Entomology Unit of the ISCIII was used. Three to six-day old female sand flies were fed on a mixture of defibrinated rabbit blood and $2.5 \times 10^{8}$ or $2.5 \times 10^{7} / \mathrm{mL}$ cultured promastigotes of JPCM5 strain or POL2FL6 isolate through a feeding device of chick skin membrane. Blood-fed female sand flies were separated and kept in a cage and after 5 days flies were transferred to oviposition pots. Some sand flies were dissected in order to evaluate the midgut infection development. Five days later which corresponded to 10 days after experimental infection, sand flies were allowed to take a second blood meal on hamsters to initiate parasite transmission. A total of four experimental infections of $P$. perniciosus with $L$. infantum promastigotes were conducted including two experimental infections with JPCM5 strain and two other with the POL2FL6 isolate.

\section{Animal infections}

Six-week-old goldhamsters (Mesocricetus auratus, strain RjHan:AURA, Janvier, France) were housed at the animal facilities of the ISCIII. Animal handling was carried out according to the standards specified in the Guide for Care and Use of Laboratory Animals and approved by the ethics committees for animal care and experimentation of the ISCIII (CBBA/4.2-PA 225/08). A total of 30 hamsters were divided into eight groups. They include four subgroups that were infected by natural transmission either with JPCM5 or POL2FL6 parasites, two subgroups of hamsters that were intraperitoneally inoculated with $10^{7}$ cultured promastigotes of JPCM5 strain and POL2FL6 isolate and a control group (uninfected). Additionally, two hamsters (Group H8) were inoculated with $10^{7}$ cultured promastigotes of BOS1FL1 isolate (Figure 1). For sand fly transmission, animals were anaesthetized with $150 \mathrm{mg} / \mathrm{kg}$ ketamine by subcutaneous route and individually placed in cages containing an average of $36(\mathrm{SD}=18)$ potentially infected sand flies, depending on the survival rate after oviposition for each sand fly infection set (Table 1). During the exposure time, a person was checking and scoring for sand fly host landing, probing or successful bloodfeeding. The site of blood-feeding was recorded to detect possible skin lesions in the area. After 1 hour, blood-fed female sand flies were dissected and their guts checked microscopically at $400 \times$ to confirm the presence of Leishmania promastigotes. The number of bites or attempts of bites received by each animal was documented.

\section{Leishmania infection follow-up}

Clinical examination and weight were recorded weekly in all animals. Animals were anaesthetized with ketamine

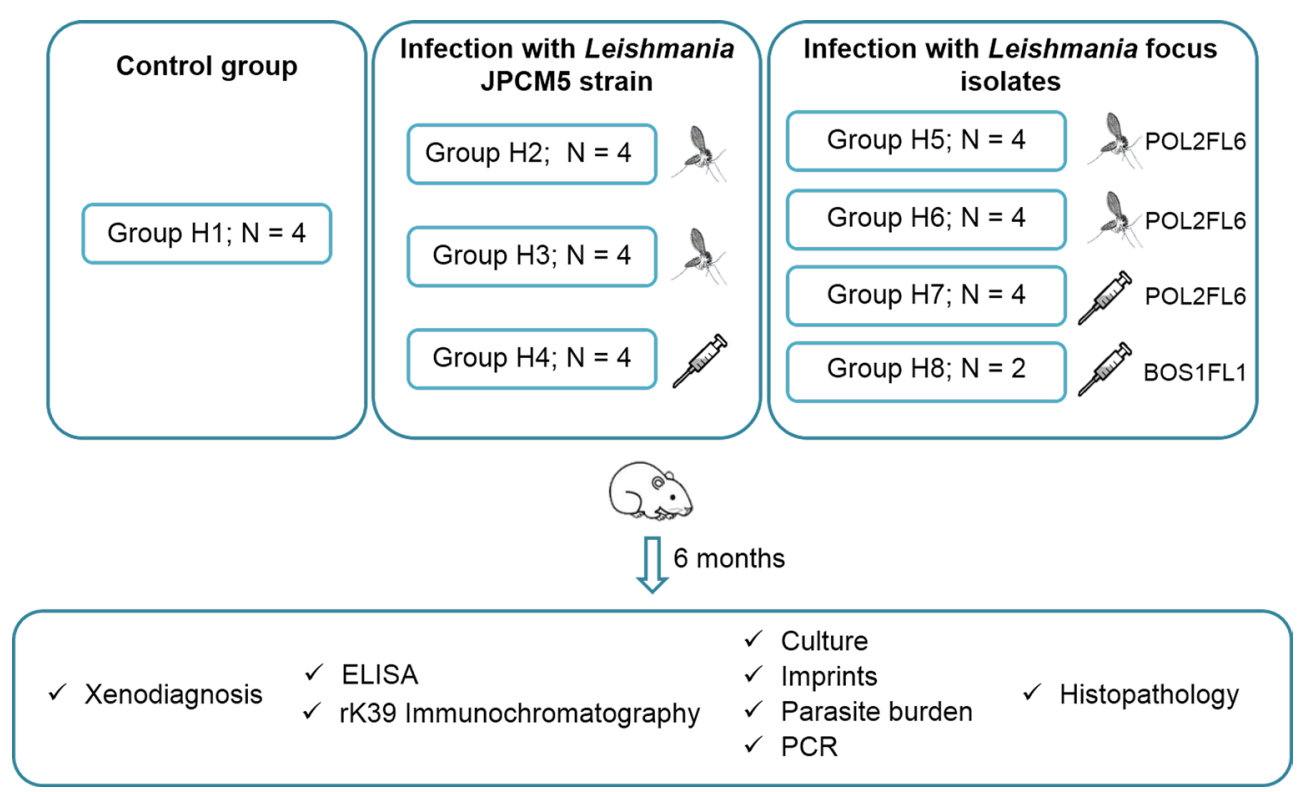

Figure 1 Working scheme of animal infections. Hamsters were split into eight groups including a control group of non-infected animals (Group H1), groups of hamsters infected with JPCM5 strain either by infective sand fly bites or by IP inoculation (Groups H2-H4) and hamsters infected with L. infantum isolates from the Madrid outbreak either by infective sand fly bites or by IP inoculation (Groups H5-H8). 
Table 1 Experimental infections of $P$. perniciosus with $L$. infantum parasites.

\begin{tabular}{lllllll}
\hline $\mathbf{N}^{\mathbf{0}}$ experiment & $\begin{array}{l}\text { Leishmania strain } \\
\text { or isolate }\end{array}$ & $\begin{array}{l}\text { Infective mixture } \\
\text { (parasites/mL) }\end{array}$ & Fed flies (\%) & $\begin{array}{l}\text { Flies transfered } \\
\text { to pots (\%) }\end{array}$ & $\begin{array}{l}\text { Surviving flies } \\
\text { after oviposition } \\
\text { (\%) }^{\mathbf{c}}\end{array}$ & $\begin{array}{l}\text { Positive } \\
\text { flies (\%) }\end{array}$ \\
\hline 1 & JPCM5 & $2.5 \times 10^{8}$ & $395 / 500(79.0)$ & $332 / 395(84.1)$ & $220 / 332(66.3)$ & $72 / 100(72.0)$ \\
2 & JPCM5 & $2.5 \times 10^{8}$ & $425 / 500(85.0)$ & $216 / 425(50.8)$ & $196 / 216(90.7)$ & $88 / 96(91.7)$ \\
3 & POL2FL6 & $2.5 \times 10^{7}$ & $317 / 500(63.4)$ & $240 / 317(75.7)$ & $150 / 240(62.5)$ & $18 / 21(85.7)$ \\
4 & POL2FL6 & $2.5 \times 10^{7}$ & $303 / 500(60.6)$ & $151 / 303(49.8)$ & $17 / 151(11.3)$ & $15 / 17(88.3)$ \\
\hline
\end{tabular}

Blood-fed sand flies/exposed sand flies $\times 100$

b Flies transferred to pots/blood-fed sand flies $\times 100$

c Flies that survived oviposition/flies transferred to pots $\times 100$

d Leishmania positive sand flies/dissected sand flies $\times 100$

and euthanized by cardiac exsanguination at 6 months after challenge. Sera were collected and stored at $-20{ }^{\circ} \mathrm{C}$ until use.

Animal necropsy was performed under sterile conditions. Liver and spleen were aseptically removed and weighed. These organs were cut into several portions that were used for the different protocols tested (culture and parasite burden, impression smears, histology or PCR).

\section{Culture, parasite burden and Giemsa-stained imprint preparation}

Reserved portions of tissues were homogenized in NET10 (10 mM Tris-HCl, $10 \mathrm{mM}$ EDTA, $10 \mathrm{mM} \mathrm{NaCl}$; pH 8.0) and passed through a cell strainer of $0.45 \mu \mathrm{m}$ (Corning, Durham, NC). Cell suspension was cultured in NNN tubes at $27^{\circ} \mathrm{C}$ that were checked weekly up to 4 weeks for promastigote detection under the microscope. Parasite burden was estimated by limit dilution assay [42]. Briefly, homogenized tissues were three-fold serially diluted with supplemented RPMI in microtiter culture plates containing a slant of NNN medium. Samples were cultured in duplicates and 24 dilutions were done. Plates were sealed and incubated at $27^{\circ} \mathrm{C}$ and after 7 days, wells were examined for motile promastigote presence using an inverted microscope. Parasite burden was expressed as the number of parasites per mg of tissue, considering that the last positive dilution contained at least one living parasite. Impression smears were Giemsa-stained and examined at 1000X under the microscope.

\section{Leishmania infantum DNA detection by PCR}

For PCR experiments, genomic DNA from $25 \mathrm{mg}$ of spleen and liver tissues was extracted using the DNeasy ${ }^{\circledR}$ Blood and Tissue Extraction Kit (QIAGEN, Hilden, Germany) according to the manufacturer's instructions. Leishmania DNA was detected by kDNA PCR reaction which is based on the amplification of a $120 \mathrm{bp}$ region of kinetoplastid DNA, as described elsewhere [43]. kDNA is an excellent target for Leishmania spp. detection that provides high sensitivity. Two hundred ng of DNA were used as the template and the following primers were used: JW11 (5'-CCTATTTTACACCAACCCCCAGT-3') and JW12 (5'-GGGTAGGGGCGTTCTGCGAAA-3'). Reliability of the technique was ensured including negative and positive controls in all molecular steps. Negative controls consisted of PCR reaction tubes both without DNA or DNA belonging to non-infected animals (Group H1). As a positive control, $60 \mathrm{pg}$ of genomic DNA extracted from JPCM5 L. infantum strain was used. PCR products were separated on Pronasafe 1.5\% agarose gels (Conda, Spain) and visualized under a UV transilluminator.

\section{Xenodiagnosis}

Infectivity of hamsters was assessed by xenodiagnosis as previously described [38]. Briefly, anaesthetized animals were individually exposed to 100 five to eight-day-old $P$. perniciosus females. Blood-fed sand flies were separated and maintained in adult cages under controlled conditions of humidity, temperature and photo-period for 5 days to allow transformation of potential amastigotes into promastigotes. Midgut dissections were carried out and sand fly infection status was determined by microscopy. Animals infected with JPCM5 strain and BOS1FL1 isolate were xenodiagnosed before sacrifice (6 months after challenge). In the case of 11 hamsters infected with POL2FL6 isolate, infectivity was thoroughly investigated and xenodiagnosis was performed at 2, 4 and 6 months.

\section{Histopathology of POL2FL6 infected hamsters}

After necropsy, all tissues were formalin-fixed, and selected bone tissue was decalcified with acetic acid. Tissue Sections. ( $3 \mu \mathrm{m}$ thick) were performed from salivary glands, stomach, small and large intestine, mesentery lymph nodes, heart, lung, kidney, adrenal glands, liver, spleen, brain, bone marrow, skin and genital tracts. In the case of skin, samples were taken from the abdomen. After hematoxylin and eosin staining, slides were examined for 
pathological lesions and the presence and quantification of Leishmania amastigotes. The parameters were scored as 0 : no amastigote detection; 1 : amastigotes hardly seen in localized areas; 2: more abundant presence of amastigotes, generally associated with other lessions such as granulomes or calcium agglomerates and 3: severe Leishmania parasitation.

\section{Leishmania serology}

Specific anti- $L$. infantum IgG antibody response generated by the analyzed animals was measured by ELISA as described elsewhere [44]. Soluble Leishmania antigen (SLA) was prepared from $L$. infantum promastigotes (JPCM5 strain). Parasites were treated with lysis buffer $(100 \mathrm{mM}$ Tris- $\mathrm{HCl}, 1 \mathrm{mM}$ EDTA, $1.6 \mathrm{mM}$ PMSF and 0.5\% protease inhibitor cocktail (Calbiochem); $\mathrm{pH}=8$ ) and disrupted by cavitation pump. Cell debris was spun down $(27000 \mathrm{~g}$, $20 \mathrm{~min}$ followed by $100000 \mathrm{~g}, 4 \mathrm{~h}$ ) and the protein content of the supernatant was determined by the Bradford method. Plates were coated with $1 \mu \mathrm{g}$ of SLA per well. Sera were diluted $1 / 200$ in $0.1 \%$ BSA $0.3 \%$ PBS-Tween and peroxidase-conjugated goat anti-hamster IgG (1:2000, Southern Biotech, Birmingham, AL, USA) was used. The enzymatic reaction was developed by orthophenylendiamine $(0.5 \mathrm{mg} /$ $\mathrm{mL}$ ) in Mcllwein phosphate citrate buffer ( $\mathrm{pH} 5.5$ ) in the presence of $0.001 \%(\mathrm{v} / \mathrm{v})$ of $\mathrm{H}_{2} \mathrm{O}_{2}(30 \%)$. Experiments were repeated at least twice. Serum dilutions from infected hamsters were considered positive when the mean of duplicate well values was greater than the cut off, calculated as the mean of the optical densisties (OD) from sera of 33 negative hamsters plus 3 times the standard deviation.

In addition, rK39 immunochromatographic tests (Kalazar Detect ${ }^{\circledR}$ Human Rapid Test; InBios, Seattle, WA, USA) were performed with sera of hamsters following manufacturer's recommendations.

\section{Statistical analysis}

Analyses were done using Prism program version 5 (GraphPad Software, Inc., San Diego, CA, USA) and statistical significance was set as $p$ value $<0.05$. Comparison between sets of groups was achieved by the non-parametric Mann-Whitney U test.

\section{Results}

\section{Sand fly infections and transmission experiments}

Each sand fly experimental infection was initiated with $500 \mathrm{P}$. perniciosus. The information regarding sand fly infection experiments including Leishmania strains, blood-feeding rates, number of sand flies transferred to oviposition pots, survival and infection rates is summarized in Table 1.

Experimental infections of P. perniciosus were achieved with infective mixtures of $L$. infantum promastigotes and rabbit blood at a final concentration of $2.5 \times 10^{8}$ parasites $/ \mathrm{mL}$ as a standard procedure in our laboratory. Infected flies with JPCM5 strain were successful in a second blood-feeding, midgut dissections showing that promastigotes had invaded the stomodeal valve and the presence of abundant metacyclic promastigotes was observed. For POL2FL6 isolate, infectious doses of $2.5 \times 10^{8}$ resulted in such a heavy infection that sand flies were not able to take a second blood meal. Therefore, a final concentration of $2.5 \times 10^{7}$ parasites $/ \mathrm{mL}$ was chosen for transmission experiments with POL2FL6 isolate. P. perniciosus infections with POL2FL6 isolate were successful as determined by massive colonization of the complete midgut including a stomodeal valve with metacyclic promastigote presence. However, many massively infected flies with POL2FL6 were still unable to take blood from hamsters, leading to a lower number of bites in animals bitten by POL2FL6-infected sand flies when compared to animals bitten by JPCM5-infected sand flies (Table 2). When working with POL2FL6 isolate, three hamsters were bitten by an individual sand fly with confirmed blood meal under the microscope. Four hamsters received long time probing of infected flies without a successful blood meal. This situation was classified as attempts of biting. There was one hamster that did not receive any bite or attempt of biting (Group H6); therefore, it was excluded from the transmission experiment.

\section{Evolution of hamster infection with JPCM5 strain and outbreak isolates}

Establishment of infection of $L$. infantum was achieved with JPCM5 strain (5/12 animals; $41.7 \%)$ and outbreak isolates (10/13 animals; $76.9 \%)$ by both routes of infection. Weekly clinical examination showed different degrees of severity according to Leishmania strain and infection route. Animals inoculated or transmitted by bite with JPCM5 strain did not show any clinical signs including weight loss during the post-infection period. Conversely, hamsters infected with POL2FL6 or BOS1FL1 isolates exhibited an apparent clinical worsening during the follow-up period, with the onset of the disease faster in the case of inoculated animals as noted by the severity of weight loss in some cases. Concretely, infected animals with outbreak isolates gained weight at a markedly slower rate than the control group. At approximately 10 weeks, animal weight reached a plateau after which infected animals with outbreak isolates sustained their weight or started to drop in the IP inoculated animals reaching weight-loss values of $25.6 \%$ (Figure 2A).

Hamsters infected with outbreak isolates showed signs of infection such as skin scaling or appearance of skin lesions affecting paws, mouth and snout (Figures 2B, $\mathrm{C}$, and $\mathrm{D})$. At necropsy, no pathological findings were 
Table 2 Data of experimentally infected hamsters.

\begin{tabular}{|c|c|c|c|c|c|c|c|c|}
\hline \multirow[t]{2}{*}{ Group } & \multirow{2}{*}{$\begin{array}{l}\text { Transmission } \\
\text { route }\end{array}$} & \multirow{2}{*}{$\begin{array}{l}\text { Leishmania strain } \\
\text { or isolate }\end{array}$} & \multirow{2}{*}{$\begin{array}{l}\text { No. of exposed } \\
\text { sand flies }^{a}\end{array}$} & \multirow{2}{*}{$\begin{array}{l}\text { No. of infective } \\
\text { bites }(\%)^{b}\end{array}$} & \multicolumn{2}{|l|}{ Culture } & \multicolumn{2}{|c|}{ Parasite burden $^{c}$} \\
\hline & & & & & Spleen & Liver & Spleen & Liver \\
\hline \multirow[t]{4}{*}{$\mathrm{H} 1$} & Control & $x$ & $x$ & $x$ & - & - & - & - \\
\hline & & & $x$ & $x$ & - & - & - & - \\
\hline & & & $x$ & $x$ & - & - & - & - \\
\hline & & & $x$ & $x$ & - & - & - & - \\
\hline \multirow[t]{4}{*}{$\mathrm{H} 2$} & Bite & JPCM5 & 55 & $14 / 55(25.5 \%)$ & + & - & - & 95 \\
\hline & & & 55 & $13 / 55(23.6 \%)$ & - & - & $4 \times 10^{2}$ & - \\
\hline & & & 55 & $16 / 55(29.1 \%)$ & - & - & - & - \\
\hline & & & 55 & $14 / 55(25.5 \%)$ & - & - & - & - \\
\hline \multirow[t]{4}{*}{$\mathrm{H} 3$} & Bite & JPCM5 & 49 & $25 / 49(51.0 \%)$ & + & - & - & - \\
\hline & & & 49 & $21 / 49(42.9 \%)$ & - & - & - & - \\
\hline & & & 49 & $14 / 49(28.6 \%)$ & - & - & - & - \\
\hline & & & 49 & $14 / 49(28.6 \%)$ & - & + & - & $3.1 \times 10^{3}$ \\
\hline \multirow[t]{4}{*}{$\mathrm{H} 4$} & $\mathbb{I P}$ & JPCM5 & $x$ & $x$ & + & - & $2.6 \times 10^{2}$ & - \\
\hline & & & $x$ & $x$ & - & - & - & - \\
\hline & & & $x$ & $x$ & - & - & - & - \\
\hline & & & $x$ & $x$ & - & - & - & - \\
\hline \multirow[t]{4}{*}{$\mathrm{H} 5$} & Bite & POL2FL6 & 25 & 1 Attemp & - & - & - & - \\
\hline & & & 25 & 1 Attemp & - & - & - & - \\
\hline & & & 25 & $>5$ Attemps & - & - & $3.3 \times 10^{5}$ & $2.9 \times 10^{4}$ \\
\hline & & & 25 & 3 Attemps & + & + & $8.8 \times 10^{12}$ & $2.0 \times 10^{10}$ \\
\hline \multirow[t]{3}{*}{ H6 } & Bite & POL2FL6 & 25 & $1 / 25$ (4.0\%) & + & - & $6.5 \times 10^{5}$ & $6.7 \times 10^{8}$ \\
\hline & & & 25 & $1 / 25(4.0 \%)$ & - & - & $1.3 \times 10^{4}$ & - \\
\hline & & & 17 & $1 / 17(5.9 \%)$ & - & - & - & - \\
\hline \multirow[t]{4}{*}{$\mathrm{H} 7$} & IP & POL2FL6 & $x$ & $x$ & + & + & $2.3 \times 10^{13}$ & $2.1 \times 10^{12}$ \\
\hline & & & $x$ & $x$ & + & + & $3.9 \times 10^{11}$ & $5.3 \times 10^{10}$ \\
\hline & & & $x$ & $x$ & + & + & $2.4 \times 10^{13}$ & $1.9 \times 10^{12}$ \\
\hline & & & $x$ & $x$ & + & + & $6.4 \times 10^{12}$ & $5.9 \times 10^{11}$ \\
\hline \multirow[t]{2}{*}{ H8 } & $\mathbb{I P}$ & BOS1FL1 & $x$ & $x$ & + & + & $3.2 \times 10^{12}$ & $9.3 \times 10^{10}$ \\
\hline & & & $x$ & $x$ & + & + & $6.3 \times 10^{13}$ & $5.9 \times 10^{12}$ \\
\hline
\end{tabular}

a The number of sand flies used for Leishmania challenge depended on the amount of female flies that survived oviposition. Survival flies were divided into cages where animals were placed for challenge

b The number of infective bites that each animal received is calculated as the number of flies that took a blood meal and was shown to be infected by Leishmania, as checked under the microscope, divided by the number of exposed flies $\times 100$

c Parasite burden is expressed as the number of parasites per gram of tissue

recorded in animals infected with JPCM5. On the contrary, most of the hamsters infected with the outbreak isolates presented severe splenomegaly when compared to spleens from uninfected animals (Figures $3 \mathrm{~A}-\mathrm{C}$ ). Spleen was often found fibrotic with pale indurations (Figure 3B). Hepatomegaly was only observed in the most severe cases of hamsters infected with outbreak isolates, although the difference among groups was not statistically significant (Figure 3A).

In animals infected with JPCM5 strain, parasites were visualized in the spleen or liver of $41.7 \%$ of hamsters by imprints, culture and/or limit dilution assay yielding low parasitic loads. Kinetoplast DNA PCR confirmed the culture results. Conversely, Leishmania parasites were detected by culture, limit dilution assay, tissue imprints (Figure 3D) or PCR in most of the animals infected with the outbreak isolates $(76.9 \%)$, which presented two-tosix fold greater parasitic loads than animals infected with JPCM5 (Table 2). In certain cases and using the same samples, parasites did not grow in cultures but were detected by limit dilution assay (i.e. H6 group) which could be a matter of better environmental growth conditions in the microtiter wells rather than in the $10 \mathrm{~mL}$ tubes.

Regarding Leishmania serology, the average readout of negative control hamsters sera was 0.12 and the cut off level was set at an OD of 0.53. None of the sera from 


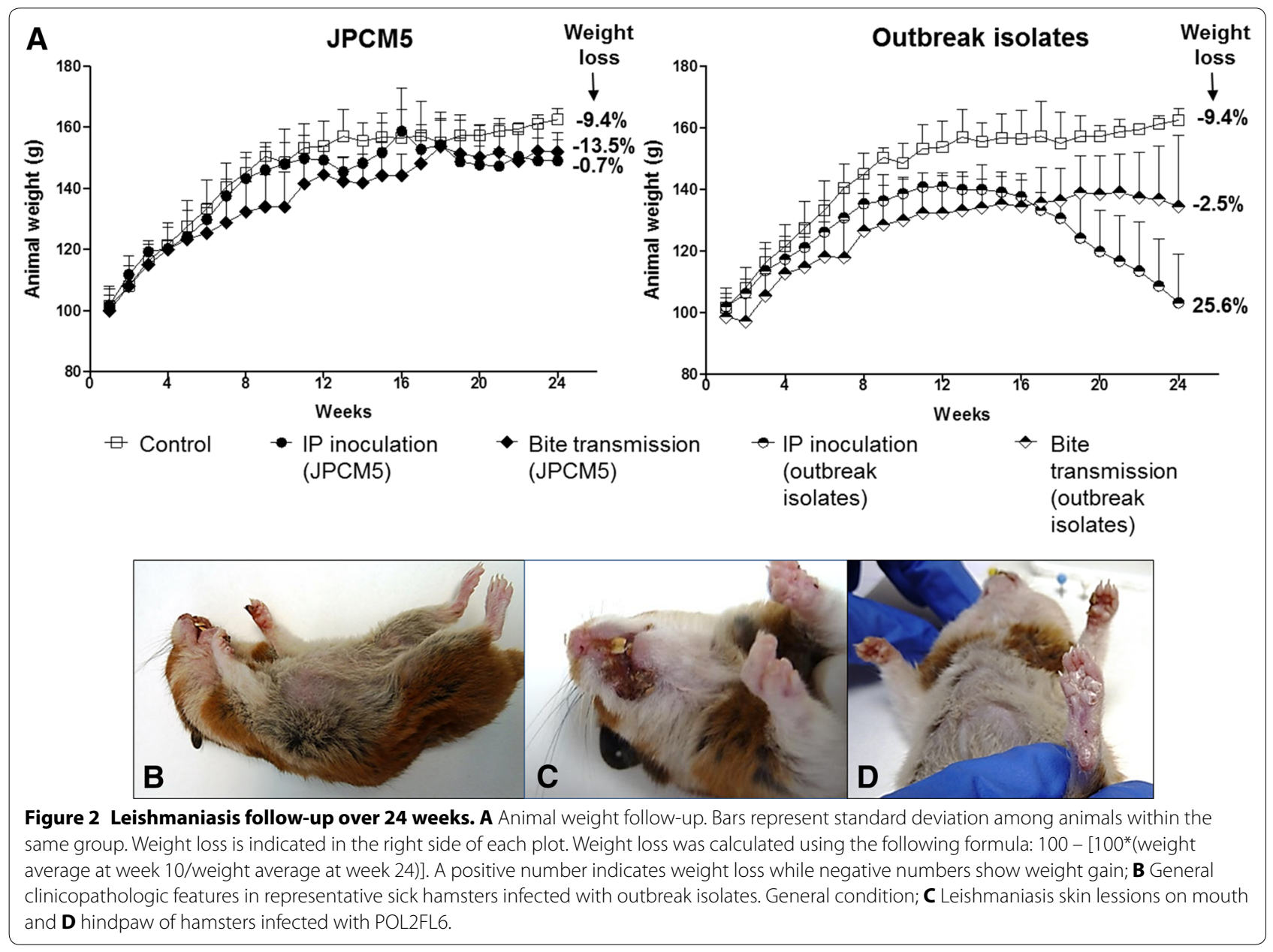

hamsters infected with JPCM5 strain presented specific IgG against the Leishmania protein extract (SLA). Nevertheless, $69.2 \%$ of the animals infected with the outbreak isolates (Groups H5-H8) showed levels of anti-Leishmania antibodies above the cut off level (Figure 3E). This positive humoral response correlated with the direct diagnosis in most of the cases (88.9\%). Immunochromatography tests (rK39) were conducted with hamster sera performing high specificity (100\%) when compared to SLA ELISA results. None of the JPCM5 infected animals showed a positive rK39 test while 6/13 (46.2\%) of hamsters infected with the outbreak isolates exhibited a positive rk39 test. Therefore, sensitivity decreased to $66.7 \%$ when compared to ELISA results. Faint recognition bands were observed even with sera that had shown high levels of anti-Leishmania antibodies in ELISA (i.e. H7.2: $\mathrm{OD}_{492}=2.2 ; \mathrm{H} 8.1: \mathrm{OD}_{492}=2.5$ and H8.2: $\mathrm{OD}_{492}=1.9$ ).

\section{Xenodiagnosis follow-up}

A total of 37 xenodiagnostic studies were carried out. Intraperitoneal inoculated hamsters with JPCM5 strain were not able to infect any sand fly by xenodiagnosis. Conversely, hamsters infected with the outbreak isolates yielded positive results in 100\% of animals IP inoculated and $43 \%$ of animals transmitted by bites. In the xenodiagnostic follow-up study, $30 \%$ of the animals infected with POL2FL6 were infective to sand flies as soon as two months post-infection. The number of positive sand flies increased over the study timeline (2-4-6 months), reaching values of $44.4 \%$ in the case of a hamster transmitted with POL2FL6 by sand fly bites (Table 3; Figures 4 and 5).

\section{Histopathology}

Leishmania amastigotes were found in several tissues of hamsters infected with POL2FL6 isolate including salivary glands, stomach, small and large intestine, mesenteric glands, lung, kidney, adrenal glands, liver, spleen, brain, bone marrow, skin and reproductive organs of hamsters. Infected inflammatory cells full of amastigote forms within the cytoplasm were abundant in the liver, spleen, bone marrow and lymphoid tissues such as mesenteric glands or Peyer's patches. Hepatic 

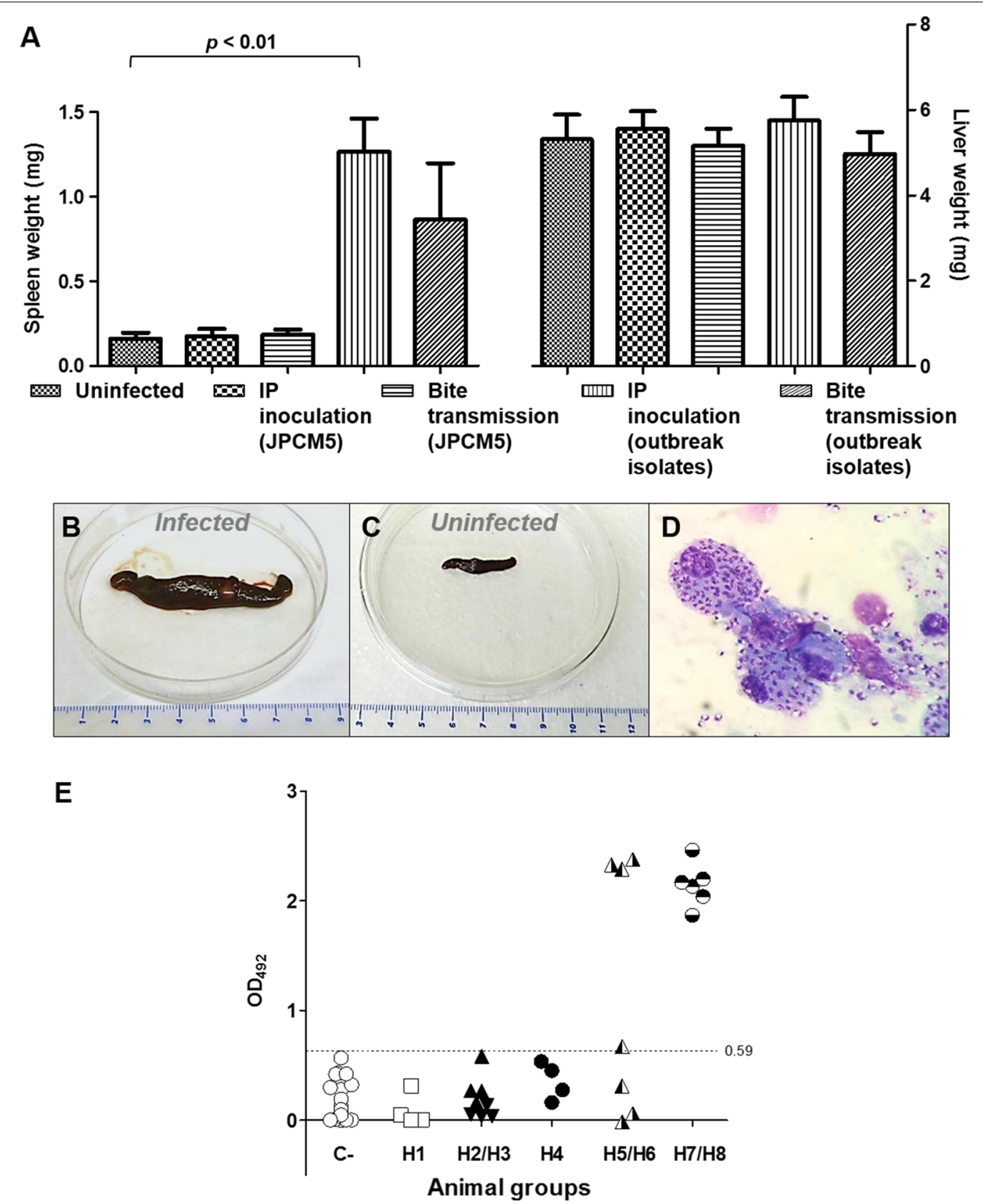

Figure 3 Spleen and liver features and anti-Leishmania humoral response of infected hamsters. A Weights of spleen and liver of animals infected with JPCM5 strain and isolates from the focus were compared with organ weights from uninfected hamsters according to the route of infection. Bars represent the standard deviation. $P<0.05$ was considered statistically significant. Spleen of hamster infected by sand fly bites with POL2FL6 showing severe splenomegaly (B) compared to spleen of non-inoculated animal (C). D Giemsa-stained imprint of spleen of hamster infected by sand fly bites with POL2FL6 showing macrophages packed with amastigotes. E Anti-L. infantum lgG antibody levels in sera of hamsters. $\mathrm{O}$ : Control animals; $\square$ : Hamster group H1; $\mathbf{\Lambda}$ : Hamster group H2; $\mathbf{\nabla}$ : Hamster group H3; $:$ Hamster group H4; $\mathbf{\Lambda}$ : Hamster group H5; $\mathbf{\Lambda}$ : Hamster group H6; : Hamster group H7; $\odot$ : Hamster group H8; 0.59 OD cut off value was established with sera of non-infected hamsters.

granulomas were present in all of the animals studied and even when amastigotes were not observed (Table 4). Granulomas and amastigote nets were also found in reproductive organs both in male and female hamsters. Amastigotes were visualized in prostatic interstice, epididymis interstice and epithelium of seminal vesicle of male inoculated animals. Moreover, granulomas with amastigotes were found in utero. Inoculated animals and some hamsters transmitted by sand fly bites showed a high degree of parasite dissemination (Table 4; Figure 6). 
Table 3 Xenodiagnosis of infected hamsters.

\begin{tabular}{|c|c|c|c|c|c|c|c|}
\hline Hamster code & Leishmania & $\begin{array}{l}\text { Transmission } \\
\text { route }\end{array}$ & $\begin{array}{l}\text { Time post- } \\
\text { infection } \\
\text { (months) }\end{array}$ & $\begin{array}{l}\text { Engorged } \\
\text { flies }(\%)^{\mathrm{a}}\end{array}$ & $\begin{array}{l}\text { Dissected } \\
\text { flies }(\%)^{\mathbf{b}}\end{array}$ & $\begin{array}{l}\text { Positive } \\
\text { flies (\%) }\end{array}$ & $\begin{array}{l}\text { Parasites } \\
\text { in s.v. }(\%)^{\text {d }}\end{array}$ \\
\hline H4.1 & JPCM5 & $\mathbb{P}$ & 6 & $94 / 100$ (94) & 65/94 (69.1) & 0 & - \\
\hline $\mathrm{H} 4.2$ & JPCM5 & IP & 6 & $81 / 100(81)$ & 70/81 (86.4) & 0 & - \\
\hline $\mathrm{H} 4.3$ & JPCM5 & IP & 6 & 87/100 (87) & 65/87 (74.7) & 0 & - \\
\hline $\mathrm{H} 4.4$ & JPCM5 & IP & 6 & $90 / 100(90)$ & 63/90 (70.0) & 0 & - \\
\hline \multirow[t]{3}{*}{ H5.1 } & POL2FL6 & Bite & 2 & 90/100 (90) & 66/90 (73.3) & 0/66 (0) & - \\
\hline & & & 4 & $81 / 100(81)$ & 73/81 (90.1) & 0/73 (0) & - \\
\hline & & & 6 & $100 / 100(100)$ & $87 / 100(87.0)$ & 0/87 (0) & - \\
\hline \multirow[t]{3}{*}{ H5.2 } & POL2FL6 & Bite & 2 & $82 / 100(82)$ & $55 / 82(67.1)$ & 0/55 (0) & - \\
\hline & & & 4 & $81 / 100(81)$ & 64/81 (79.0) & 0/64 (0) & - \\
\hline & & & 6 & 99/100 (99) & 79/99 (79.8) & $0 / 79(0)$ & - \\
\hline \multirow[t]{3}{*}{ H5.3 } & POL2FL6 & Bite & 2 & 100/100 (100) & $54 / 100(54.0)$ & 2/54 (3.7) & $2 / 2(100 \%)$ \\
\hline & & & 4 & 84/100 (84) & 72/84 (85.7) & 4/72 (5.6) & 4/4 (100\%) \\
\hline & & & 6 & 93/100 (93) & 71/93 (76.3) & $5 / 71(7.0)$ & 4/5 (80.0\%) \\
\hline \multirow[t]{3}{*}{$\mathrm{H} 5.4$} & POL2FL6 & Bite & 2 & 87/100 (87) & 67/87 (77.0) & $1 / 67(1.4)$ & $1 / 1(100 \%)$ \\
\hline & & & 4 & 88/100 (88) & 77/88 (87.5) & $7 / 77$ (9.1) & 7/7 (100\%) \\
\hline & & & 6 & 99/100 (99) & 81/99 (81.8) & 36/81 (44.4) & $33 / 36(91.7 \%)$ \\
\hline \multirow[t]{3}{*}{ H6.1 } & POL2FL6 & Bite & 2 & 96/100 (96) & 67/96 (69.8) & $0 / 67(0)$ & - \\
\hline & & & 4 & $46 / 100(46)$ & $39 / 46(84.8)$ & $0 / 39(0)$ & - \\
\hline & & & 6 & $100 / 100(100)$ & $86 / 100(86.0)$ & $1 / 86(1.2)$ & $1 / 1(100 \%)$ \\
\hline \multirow[t]{3}{*}{ H6.2 } & POL2FL6 & Bite & 2 & $90 / 100(90)$ & $67 / 90(74.4)$ & $0 / 67(0)$ & - \\
\hline & & & 4 & $90 / 100(90)$ & 28/90 (31.1) & 0/28 (0) & - \\
\hline & & & 6 & 95/100 (95) & 69/95 (68.4) & 0/69 (0\%) & - \\
\hline \multirow[t]{3}{*}{ H6.3 } & POL2FL6 & Bite & 2 & 98/100 (98) & $81 / 98$ (82.7) & 0/81 (0) & - \\
\hline & & & 4 & 99/100 (99) & 89/99 (89.9) & 0/89 (0) & - \\
\hline & & & 6 & 99/100 (99) & 86/99 (86.8) & 0/86 (0) & - \\
\hline \multirow[t]{3}{*}{ H7.1 } & POL2FL6 & IP & 2 & $92 / 100(92)$ & 53/92 (57.6) & $4 / 53(7.5)$ & 4/4 (100\%) \\
\hline & & & 4 & $92 / 100(92)$ & 33/92 (35.9) & $3 / 33(9.1)$ & $2 / 3(66.7 \%)$ \\
\hline & & & 6 & $100 / 100(100)$ & $83 / 100(83.0)$ & 21/83 (25.3) & 5/21 (23.8\%) \\
\hline \multirow[t]{3}{*}{$\mathrm{H} 7.2$} & POL2FL6 & $\mathbb{P}$ & 2 & 72/100 (72) & 28/72 (38.9) & $0 / 28(0)$ & - \\
\hline & & & 4 & 97/100 (97) & 92/97 (94.8) & 17/92 (18.5) & 9/17 (52.9\%) \\
\hline & & & 6 & 89/100 (89) & 62/89 (69.7) & 13/62 (21.0) & $11 / 13(84.6 \%)$ \\
\hline \multirow[t]{3}{*}{$\mathrm{H} 7.3$} & POL2FL6 & $\mathbb{P}$ & 2 & $92 / 100(92)$ & 39/92 (42.2) & 0/39(0) & - \\
\hline & & & 4 & 71/100 (71) & $59 / 71(83.1)$ & $4 / 59(6.8)$ & 3/4 (75.0\%) \\
\hline & & & 6 & $91 / 100(91)$ & $81 / 91$ (89.0) & 23/81 (28.4) & 19/23 (82.6\%) \\
\hline $\mathrm{H} 7.4$ & POL2FL6 & $\mathbb{P}$ & 6 & 96/100 (96) & 72/96 (75.0) & $3 / 72(4.2)$ & $0(0 \%)$ \\
\hline H8.1 & BOS1FL1 & IP & 6 & 94/100 (94) & 93/94 (98.9) & 11/93 (11.8) & 5/11 (45.5\%) \\
\hline H8.2 & BOS1FL1 & $\mathbb{P}$ & 6 & 97/100 (97) & 83/97 (85.6) & $15 / 83(18.1)$ & 6/15 (40.0\%) \\
\hline
\end{tabular}

Metacyclic promastigotes were observed in s. v. of all sand flies examined

a Blood-fed sand flies/exposed sand flies $\times 100$

b Dissected sand flies/total fed flies $\times 100$

c Leishmania positive sand flies/dissected sand flies $\times 100$

d Maturity of infection is estimated as the percentage of sand flies with promastigotes in the stomodeal valve (s. v.)

Besides some degree of calcium deposition was observed in tissues from the non-infected hamster, agglomerates were frequently seen in most of infected analyzed tissues as a sign of infection and amastigote nests were usually found nearby.

\section{Discussion}

The high virulence of two L. infantum isolates that are circulating in the Madrid LV outbreak was stressed using a hamster model. Establishment of infection of L. infantum was achieved with JPCM5 strain and 


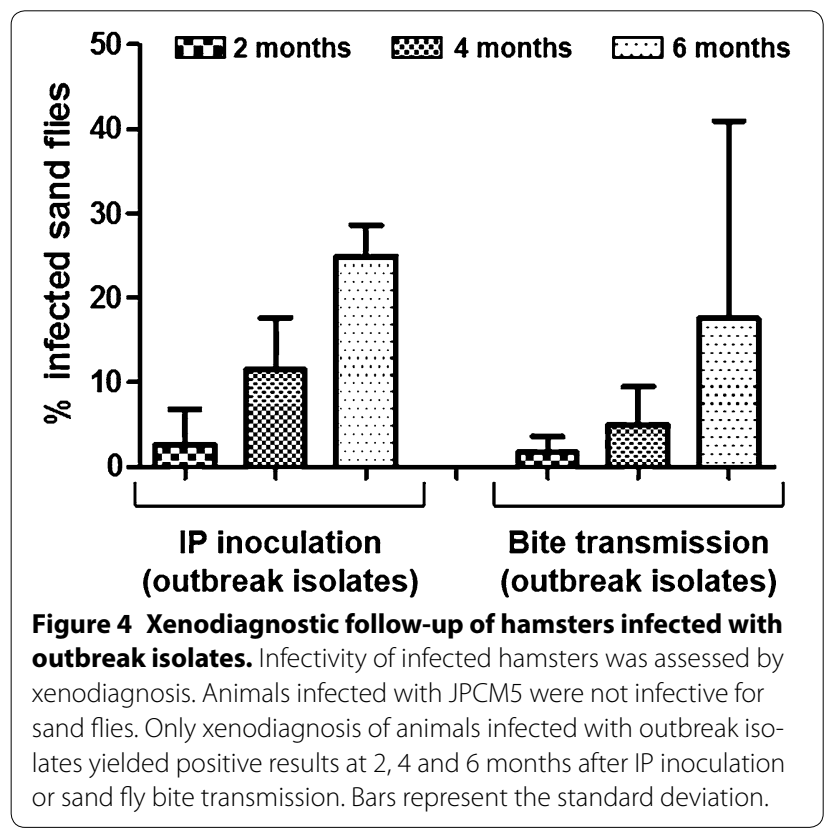

outbreak isolates both by $P$. perniciosus infective bites or IP route. However, virulence of outbreak isolates was highlighted by the worse clinical outcome of disease, higher parasite detection in the spleen and liver, greater parasitic loads and positivity of Leishmania serology when compared with hamsters infected with JPCM5 strain.

Natural transmission models are crucial for studying immunological processes of leishmaniasis disease. The need for developing these models was clearly evident when vaccination protected mice against needle challenge but failed to protect animals against infected sand fly challenge $[45,46]$. In this case, a natural Leishmania transmission model helped us to confirm the great virulence of outbreak isolates that was also observed with IP inoculation. However, a better standardization of the natural model is required for future use. More precisely, the number of parasites for sand fly infections should be titrated for sand fly infections and lower concentrations should be selected. Besides, implementing
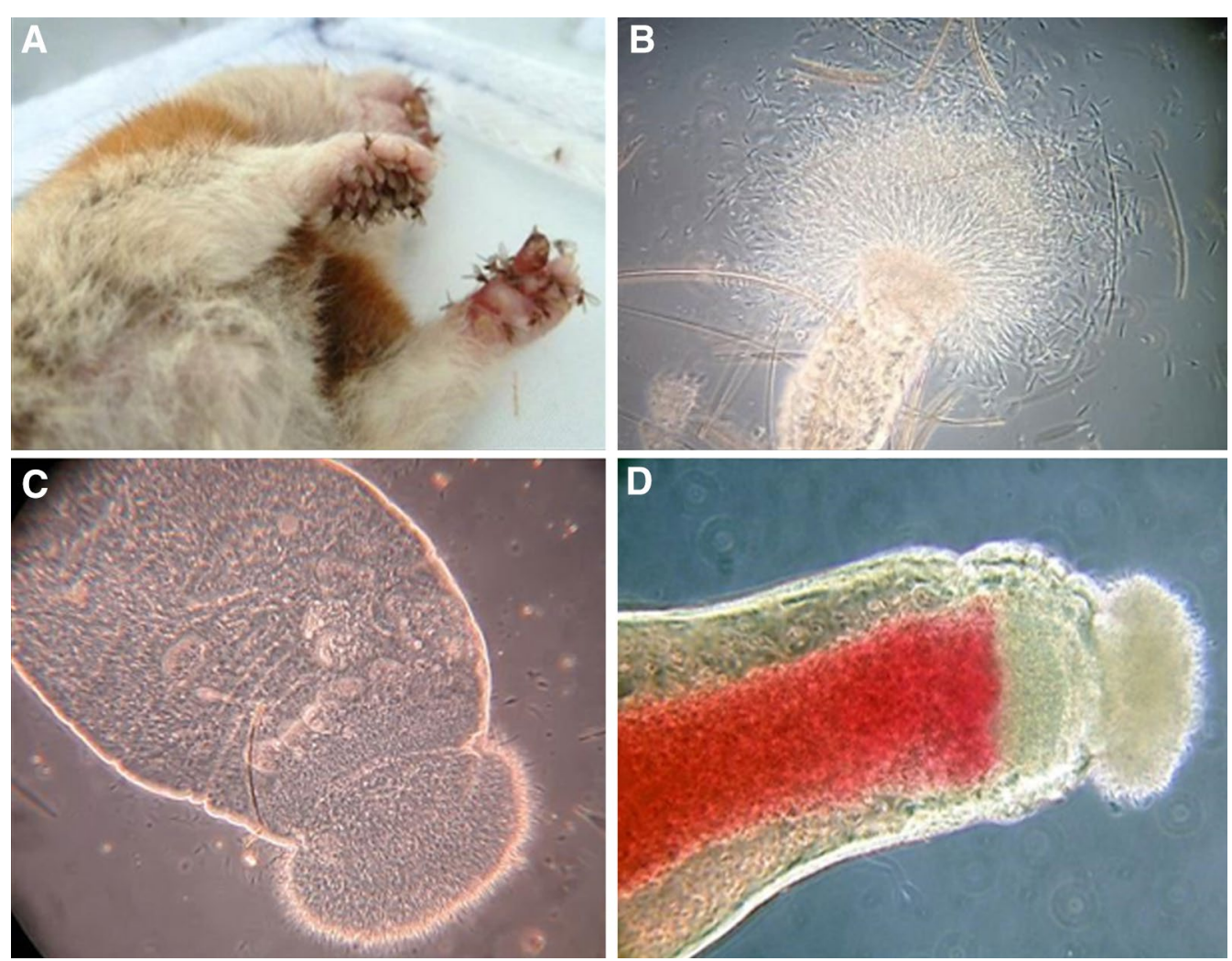

Figure 5 Sand fly experimental infections and xenodiagnostic studies. A Colonized P. perniciosus taking a blood meal from animal paws of anesthetized hamster during xenodiagnosis; B Midgut dissection of P. perniciosus infected with POL2FL6 5 days after xenodiagnosis, with motile promastigotes coming out of the anterior part; C Midgut of an infected sand fly showing an enlarged stomodeal valve; D Midgut dissection of experimentally infected P. perniciosus after biting on a hamster (re-feeding) and thus, potentially transmitting Leishmania parasites. 
Table 4 Histopathology of several POL2FL6 infected hamsters.

\begin{tabular}{|c|c|c|c|c|c|c|c|c|c|}
\hline Tissue & Negative control & H5.3 & H5.4 & H6.1 & H6.2 & H6.3 & H7.1 & $\mathrm{H} 7.2$ & H7.3 \\
\hline Salivary glands & 0 & ND & 1 & 0 & ND & 0 & 1 & 1 & 0 \\
\hline Stomach & 0 & ND & 2 & 0 & ND & 0 & 2 & 2 & 1 \\
\hline Small intestine & 0 & ND & 2 & 0 & 0 & 0 & 2 & 2 & 2 \\
\hline Large intestine & 0 & ND & 1 & 0 & 0 & 0 & 1 & 1 & 1 \\
\hline Mesenteric ganglion & 0 & ND & 3 & 0 & 0 & 0 & 3 & 3 & 3 \\
\hline Heart & 0 & ND & 0 & 0 & 0 & 0 & 0 & 0 & 0 \\
\hline Lung & 0 & ND & 1 & 0 & 0 & 0 & 1 & 1 & 1 \\
\hline Kidney & 0 & ND & 0 & 1 & 0 & 0 & 1 & 1 & 1 \\
\hline Adrenal gland (cortex) & 0 & ND & 2 & 0 & 0 & 0 & 1 & 1 & 1 \\
\hline Liver & 0 & 0 & 3 & 0 & 0 & 0 & 3 & 3 & 3 \\
\hline Spleen & 0 & 0 & 3 & 0 & 0 & 0 & 3 & 3 & 3 \\
\hline Pancreas & 0 & ND & 0 & 0 & 0 & 0 & 0 & 0 & 0 \\
\hline Brain & 0 & ND & 0 & 0 & 0 & 0 & 1 & 1 & 0 \\
\hline Bone marrow & 0 & ND & 3 & 0 & 0 & ND & ND & ND & ND \\
\hline Skin & 0 & ND & 1 & 0 & 0 & 0 & ND & 0 & ND \\
\hline Reproductive organs & 0 & ND & 3 & 0 & 0 & 0 & 2 & 1 & 1 \\
\hline
\end{tabular}

Negative control corresponds to a non infected hamster. H5.3, H5.4: Group 5, hamsters 3 and 4 (Leishmania vector-initiated infection). H6.1, H6.2, H6.3: Group 6, hamsters 1, 2 and 3 (Leishmania vector-initiated infection). H7.1, H7.2, H7.3: Group 7, hamsters 1, 2 and 3 (Leishmania intraperitoneal inoculation)

ND, not determined; 0 , no amastigote detection; 1 , amastigotes hardly seen in localized areas; 2 , more abundant presence of amastigotes, generally associated with other lessions such as granulomes or calcium agglomerates and 3, severe Leishmania parasitation

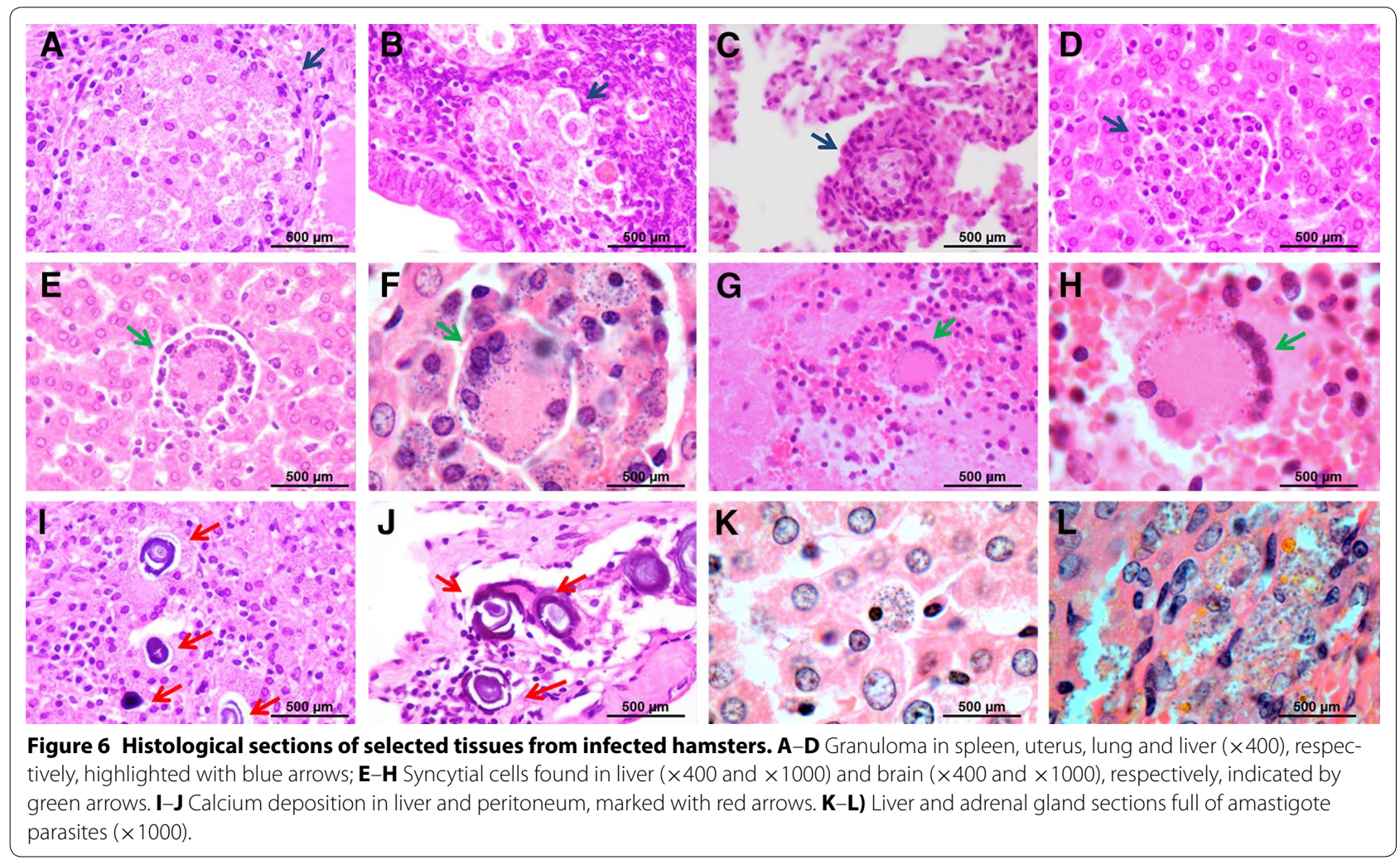

posttransmission scoring and metacyclic abundance determination would be useful to assess the rate of mature infection within a group.
Noteworthy, the entire L. infantum cycle was accomplished under laboratory conditions. Therefore, parasites originally isolated from collected sand flies in the field 
were used to infect hamsters throught the bite of experimentally infected colonized P. perniciosus. Morover, parasites were recovered by sand flies by xenodiagnosis.

Our results indicate that infection by syringe is more consistent than transmission by bite. In the case of the outbreak isolates, intraperitoneal inoculation leaded to severe clinical outcome in all animals (Groups H7 and H8). However, in animals infected by sand fly bites, disease development was more variable showing different degrees of clinical signs (Groups H5 and H6). This variability can be considered a more accurate reflection of what occurs in nature and it has already been described in hamsters infected with Leishmania chagasi by the bite of infected L. longipalpis [28]. This unpredictable outcome of clinical disease may be related to the individual variability of Leishmania doses ejected by infected sand flies $[10,11]$. Furthermore, Kimblin et al. [10] correlated a rapid development of large lessions in the ears of mice that received the high-dose inoculum $\left(5.6 \times 10^{3}\right.$ promastigotes).

Under laboratory conditions, natural transmission experiments are mainly hampered since the majority of sand flies die after oviposition in the laboratory [47]. Survival rates were improved by delaying to 5 days the time after blood-feeding before transferring the sand flies to oviposition pots. Experimental infections of $P$. perniciosus with both JPCM5 strain and POL2FL6 isolate resulted in heavy infections with metacyclic promastigotes blocking the stomodeal valve. However, several differences in terms of infection status were found. Sand fly infections with POL2FL6 isolate were massive; midguts were packed with great numbers of highly motile promastigotes and stomodeal valves were completely blocked. Those heavily infected sand flies were unable to re-feed but one bite or even attempts of biting without imbibing blood were sufficient for transmission with POL2FL6 isolate. Leishmania is known to modify sand fly biting behavior. Such interference in feeding behavior results in a greater number of bites by females attempting to take blood, thus favoring the transmission chances to a higher number of hosts in nature $[15,18]$. Parasite transmission only by probing sand flies has been demonstrated for CL $[18,19,47-49]$ as well as for VL [50].

We would like to remark that the differences found in midgut colonization should be considered for further investigation, since the massive colonization of outbreak isolates can determine the vector capacity. Moreover, massive colonization of midgut and stomodeal valve was also observed in natural infections from field sand flies collected in the outbreak area (unpublished observations).

Regarding Leishmania serology, in most of the cases infection with the outbreak isolates elicited a high titer of specific IgG. However, rk39 immunochromatography performed with the same sera resulted in a lower sensitivity compared to the ELISA tests (66.7\%). Even sera showing high titers of IgG anti-SLA gave faint bands in the rk39 immunochromatography commercial tests. This might be due to the slight binding affinity of protein A to the Fc receptor of hamster IgG [51].

Due to the high virulence observed in POL2FL6 isolate a deeper insight into the dissemination process of these parasites in different vertebrate tissues was gained. Histopathology studies confirmed the wide spread of POL2FL6 parasites. Spleen, liver, bone marrow and lymph nodes were found highly parasitized. These organs are largely known to be involved in leishmaniasis pathology [52]. On the contrary, amastigote forms were found in other not so common or less studied locations such as salivary glands, stomach, intestine, mesenteric glands, lung, kidney, adrenal glands, brain and reproductive organs of the hamster. The presence of amastigotes in renal, gastrointestinal and respiratory systems has been described [52-54] and even in the central nervous system of experimentally infected hamsters and naturally infected dogs [55, 56]. Surprisingly, parasites were found in the skin of only one animal. Taking into consideration that hamsters infected with POL2FL6 isolate gave high rates of infected sand flies as evaluated by xenodiagnosis, visualization of parasites was expected in all skin samples. Future studies are planned to further investigate the dissemination of different parasite strains along the skin and its relationship with sand fly infectiousness.

Transmission by bite of POL2FL6 isolate generated a slower progression of clinical disease than IP infection providing a better reflection of the chronicity that takes place in nature. However, both groups were infective to P. perniciosus by xenodiagnosis as soon as 2 months postinfection. Conversely, hamsters inoculated with JPCM5 were not infective to sand flies. In our experiments, the capability to transmit Leishmania parasites from infected animals to sand flies is related to the disease progression. This relationship between clinical severity and proportion of infectious dogs has been widely reported [57]. Similarly, hamsters showing worse clinical conditions exhibited higher infectivity rates to sand flies. Moreover, this association was clearly demonstrated as the infectiousness of hamsters infected by POL2FL6 to sand flies increased over time reaching values of $44.4 \%$ for a vectorinitiated infection.

POL2FL6 isolate produced massive infections in sand flies, and both BOS1FL1 and POL2FL6 caused severe clinical manifestations in hamsters. Animals infected with the outbreak isolates exhibited high infectiousness to sand flies. Therefore, this result supports the great virulence of the two studied Leishmania isolates that are circulating in the focus of VL in Madrid. So far, molecular 
characterization of Leishmania isolates from the focus share the same ITS genotype as the strain MHOM/ ES/87/LOMBARDI [58]. LOMBARDI strain was initially isolated in 1987 from a CL patient in Spain (region unknown). Chicharro et al. typed human Leishmania isolates to get an epidemiologic picture of two periods (before: 1988-2005 and during the outbreak: 2008-2012) and found out that this genotype has been circulating in Madrid since at least 1992 [58]. This is the only ITS type found in isolates from all human cases associated with this outbreak. Besides human cases, ITS-LOMBARDI is also present in field sand flies and in hares and rabbits from the focus area. This genotype has been found both in isolates from CL and VL patients [58]. Therefore, no specific tropism has been assigned to this ITS genotype. Recently, virulence of $L$. infantum isolates from $P$. perniciosus captured in the focus area was highlighted using an ex vivo model [59]. These authors showed that BOS1FL1 and POL2FL7 isolates displayed high virulence in terms of infection rates of murine macrophages and dendritic cells, cytokine production and enzymatic activities, undermining host immune defense mechanisms. The experiments included in this study with in vivo natural transmission models serve to complement the ex vivo analyses. The high virulence of these isolates is consistent with the outbreak of leishmaniasis of Madrid and could explain its magnituide, since it is considered the largest focus of VL described in Europe so far.

This natural infection model allowed us to compare Leishmania strain virulence and infectivity to sand flies. The virulence of isolates that are circulating in the focus of leishmaniasis in Madrid has been highlighted by the worse clinical outcome of disease, higher parasitic loads in spleen and liver and positivity of Leishmania serology when compared with hamsters infected with JPCM5 strain. Histopathological studies confirmed the wide spread of POL2FL6 parasites to several organs of hamsters and only animals infected with outbreak isolates were infective to sand flies in xenodiagnostic studies. These findings would contribute to a better understanding of the epidemiology of the largest focus of VL in Europe.

\section{Competing interests}

The authors declare that they have no competing interests.

\section{Authors' contributions \\ Conceived and designed the experiments: RM, MJ. Performed the experi- ments: IMM, RM, MJ, CE. Collaborated and supported on performance of the tests: EG. Analyzed the data: IMM. Wrote the final manuscript: IMM, MJ, RM. All authors read and approved the final manuscript.}

\section{Acknowledgements}

This study was partially funded by the Spanish Ministry of Science \& Innovation (Project AGL2008-01592) and by the EU grant FP7-2011-261504 EDENext. The paper is catalogued by the EDENext Steering Committee as EDENext372. We would like to thank the Veterinary Unit (ISCIII) for animal handling,
Histopathology Unit (ISCIII) for histology sections preparation, Sonia Hernández for excellent sand fly rearing and Ancare Velasco for technical work.

We would like to dedicate this work to the memory of Cesar Eguiluz who sadly passed away during the course of revision of this paper.

\section{Author details}

${ }^{1}$ Unidad de Entomología Médica, Servicio de Parasitología, Centro Nacional de Microbiología, Instituto de Salud Carlos III, Ctra. Majadahonda-Pozuelo s/n Majadahonda, 28220 Madrid, Spain. ${ }^{2}$ Unidad de Veterinaria, Centro Nacional de Microbiología, Instituto de Salud Carlos III, Ctra. Majadahonda-Pozuelo s/n, Majadahonda, 28220 Madrid, Spain.

Received: 17 April 2015 Accepted: 5 October 2015

Published online: 09 December 2015

\section{References}

1. Alvar J, Vélez ID, Bern C, Herrero M, Desjeux P, Cano J, Jannin J, den Boer M, Leishmaniasis Control Team WHO (2012) Leishmaniasis worldwide and global estimates of its incidence. PLoS One 7:e35671

2. WHO (2010) Control of the Leishmaniases. World Health Organization, Geneva, Tech Rep Ser no. 949

3. Garg R, Dube A (2006) Animal models for vaccine studies for visceral leishmaniasis. Indian J Med Res 123:439-454

4. Dea-Ayuela MA, Rama-Iniguez S, Alunda JM, Bolas-Fernandez F (2007) Setting new immunobiological parameters in the hamster model of visceral leishmaniasis for in vivo testing of antileishmanial compounds. Vet Res Commun 31:703-717

5. Requena JM, Soto M, Doria MD, Alonso C (2000) Immune and clinical parameters associated with Leishmania infantum infection in the golden hamster model. Vet Immunol Immunopathol 76:269-281

6. Loria-Cervera EN, Andrade-Narvaez FJ (2014) Animal models for the study of leishmaniasis immunology. Rev Inst Med Trop Sao Paulo 56:1-11

7. Nieto A, Dominguez-Bernal G, Orden JA, De La Fuente R, Madrid-Elena N, Carrion J (2011) Mechanisms of resistance and susceptibility to experimental visceral leishmaniosis: BALB/c mouse versus syrian hamster model. Vet Res 42:39

8. Randolph SE, Nuttall PA (1994) Nearly right or precisely wrong? Natural versus laboratory studies of vector-borne diseases. Parasitol Today $10: 458-462$

9. Rogers ME, Ilg T, Nikolaev AV, Ferguson MA, Bates PA (2004) Transmission of cutaneous leishmaniasis by sand flies is enhanced by regurgitation of fPPG. Nature 430:463-467

10. Kimblin N, Peters N, Debrabant A, Secundino N, Egen J, Lawyer P, Fay MP, Kamhawi S, Sacks D (2008) Quantification of the infectious dose of Leishmania major transmitted to the skin by single sand flies. Proc Natl Acad Sci U S A 105:10125-10130

11. Maia C, Seblova V, Sadlova J, Votypka J, Volf P (2011) Experimental transmission of Leishmania infantum by two major vectors: a comparison between a viscerotropic and a dermotropic strain. PLoS Negl Trop Dis 5:e1181

12. Secundino NF, Freitas VC, Monteiro CC, Pires AC, David BA, Pimenta PF (2012) The transmission of Leishmania infantum chagasi by the bite of the Lutzomyia longipalpis to two different vertebrates. Parasit Vectors 5:20

13. Titus RG, Ribeiro JM (1988) Salivary gland lysates from the sand fly Lutzomyia longipalpis enhance Leishmania infectivity. Science 239:1306-1308

14. Belkaid Y, Kamhawi S, Modi G, Valenzuela J, Noben-Trauth N, Rowton E, Ribeiro J, Sacks DL (1998) Development of a natural model of cutaneous leishmaniasis: powerful effects of vector saliva and saliva preexposure on the long-term outcome of Leishmania major infection in the mouse ear dermis. J Exp Med 188:1941-1953

15. Rogers ME (2012) The role of leishmania proteophosphoglycans in sand fly transmission and infection of the Mammalian host. Front Microbiol 3:223

16. Moreno I, Molina R, Toraño A, Laurín E, García E, Domínguez M (2007) Comparative real-time kinetic analysis of human complement killing of Leishmania infantum promastigotes derived from axenic culture or from Phlebotomus perniciosus. Microb Infect 9:1574-1580 
17. Sacks DL, Melby PC (2015) Animal models for the analysis of immune responses to leishmaniasis. Curr Protoc Immunol 108:19.2.1-19.2.24

18. Beach R, Kiilu G, Leeuwenburg J (1985) Modification of sand fly biting behavior by Leishmania leads to increased parasite transmission. Am J Trop Med Hyg 34:278-282

19. Svobodova M, Votypka J (2003) Experimental transmission of Leishmania tropica to hamsters and mice by the bite of Phlebotomus sergenti. Microb Infect 5:471-474

20. Kamhawi S, Belkaid Y, Modi G, Rowton E, Sacks D (2000) Protection against cutaneous leishmaniasis resulting from bites of uninfected sand flies. Science 290:1351-1354

21. Gomes R, Teixeira C, Oliveira F, Lawyer PG, Elnaiem DE, Meneses C, Goto Y, Bhatia A, Howard RF, Reed SG, Valenzuela JG, Kamhawi S (2012) KSAC, a defined Leishmania antigen, plus adjuvant protects against the virulence of L. major transmitted by its natural vector Phlebotomus duboscai. PLoS Negl Trop Dis 6:e1610

22. Abi Abdallah DS, Pavinski Bitar A, Oliveira F, Meneses C, Park JJ, Mendez S, Kamhawi S, Valenzuela JG, Marquis H (2014) A Listeria-based vaccine that secretes the sand fly salivary protein LJM11 confers long-term protection against vector-transmitted Leishmania major. Infect Immun 82:2736-2745

23. Teixeira C, Gomes R, Oliveira F, Meneses C, Gilmore DC, Elnaiem DE, Valenzuela JG, Kamhawi S (2014) Characterization of the early inflammatory infiltrate at the feeding site of infected sand flies in mice protected from vector-transmitted Leishmania major by exposure to uninfected bites. PLoS Negl Trop Dis 8:e2781

24. Lawyer PG, Githure Jl, Anjili CO, Olobo JO, Koech DK, Reid GD (1990) Experimental transmission of Leishmania major to vervet monkeys (Cercopithecus aethiops) by bites of Phlebotomus duboscai (Diptera: Psychodidae). Trans R Soc Trop Med Hyg 84:229-232

25. Oliveira F, Rowton E, Aslan H, Gomes R, Castrovinci PA, Alvarenga PH, Abdeladhim M, Teixeira C, Meneses C, Kleeman LT, Kleeman LT, Guimaraes-Costa AB, Rowland TE, Gilmore D, Doumbia S, Reed SG, Lawyer PG, Andersen JF, Kamhawi S, Valenzuela JG (2015) A sand fly salivary protein vaccine shows efficacy against vector-transmitted cutaneous leishmaniasis in nonhuman primates. Sci Transl Med 7:290ra90

26. Rioux JA, Killick-Kendrick R, Leaney AJ, Young CJ, Turner DP, Lanotte G, Bailly M (1979) Ecology of leishmaniasis in the south of France. 11. Canine leishmaniasis: successful experimental transmission from dog to dog by the bite of Phlebotomus ariasi Tonnoir, 1921 (author's transl). Ann Parasitol Hum Comp 54:401-407 (in French)

27. Knechtli R, Jenni L (1990) Experimental transmission of Leishmania infantum by the bite of Phlebotomus perniciosus from Switzerland. Acta Trop 47:213-216

28. Lainson R, Ward RD, Shaw JJ (1977) Experimental transmission of Leishmania chagasi, causative agent of neotropical visceral leishmaniasis, by the sandfly Lutzomyia longipalpis. Nature 266:628-630

29. Pozio E, Maroli M, Gradoni L, Gramiccia M (1985) Laboratory transmission of Leishmania infantum to Rattus rattus by the bite of experimentally infected Phlebotomus perniciosus. Trans R Soc Trop Med Hyg 79:524-526

30. Aslan H, Dey R, Meneses C, Castrovinci P, Jeronimo SM, Oliva G, Fischer L, Duncan RC, Nakhasi HL, Valenzuela JG, Kamhawi S (2013) A new model of progressive visceral leishmaniasis in hamsters by natural transmission via bites of vector sand flies. J Inf Dis 207:1328-1338

31. Goncalves MD, Ryan L, Lainson R, Shaw JJ (1985) The retained capacity of Lutzomyia longipalpis (Lutz \& Neiva) to transmit Leishmania chagasi (Cunha \& Chagas) after eight years (64 generations) in a closed laboratory colony. Mem Inst Oswaldo Cruz 80:337-338

32. El Sawaf BM, Doha SA, Imam MI (2012) Transmission of Leishmania infantum MON-98 to hamsters by the bite of Phlebotomus langeroni Nitzulescu (Diptera: psychodidae). Acta Trop 121:44-46

33. Sadlova J, Seblova V, Votypka J, Warburg A, Volf P (2015) Xenodiagnosis of Leishmania donovani in BALB/c mice using Phlebotomus orientalis: a new laboratory model. Parasit Vectors 8:765

34. Arce A, Estirado A, Ordobás M, Sevilla S, García N, Moratilla L, de la Fuente S, Martínez A, Pérez A, Arangúez E, Iriso A, Sevillano O, Bernal J, Vilas F (2013) Re-emergence of leishmaniasis in Spain: community outbreak in Madrid, Spain, 2009-2012. Euro Surveill 18:20546

35. Vilas F, Carpintero J, Sevilla S, Martínez A, Ordobás M, Bernal J, Díaz R, Iriso A, Sevillano O, Escacena C, De La Fuente S, Arce A, Estirado A, Frutos J, Fúster F (2012) Brote de leishmaniasis en la zona suroeste de la
Comunidad de Madrid. Medidas de investigación y control medioambiental. Prof Vet 17:6-15 (in Spanish)

36. Gálvez R, Miró G, Descalzo MA, Nieto J, Dado D, Martín O, Cubero E, Molina R (2010) Emerging trends in the seroprevalence of canine leishmaniasis in the Madrid region (central Spain). Vet Parasitol 169:327-334

37. Jiménez M, González E, Martín-Martín I, Hernández S, Molina R (2014) Could wild rabbits (Oryctolagus cuniculus) be reservoirs for Leishmania infantum in the focus of Madrid, Spain? Vet Parasitol 202:296-300

38. Molina R, Jiménez MI, Cruz I, Iriso A, Martín-Martín I, Sevillano O, Melero S, Bernal J (2012) The hare (Lepus granatensis) as potential sylvatic reservoir of Leishmania infantum in Spain. Vet Parasitol 190:268-271

39. Wellcome Trust Sanger Institute. https://www.sanger.ac.uk/resources/ downloads/protozoa/leishmania-infantum.html. Accessed 12 Oct 2015

40. Denise H, Poot J, Jimenez M, Ambit A, Herrmann DC, Vermeulen AN, Coombs GH, Mottram JC (2006) Studies on the CPA cysteine peptidase in the Leishmania infantum genome strain JPCM5. BMC Mol Biol 7:42

41. Molina R (1991) Laboratory adaptation of an autochthonous colony of Phlebotomus perniciosus Newstead, 1911 (Diptera: Psychodidae). Res Rev Parasitol 51:87-89

42. Titus RG, Marchand M, Boon T, Louis JA (1985) A limiting dilution assay for quantifying Leishmania major in tissues of infected mice. Parasite Immunol 7:545-555

43. Jiménez M, González E, Iriso A, Marco E, Alegret A, Fuster F, Molina R (2013) Detection of Leishmania infantum and identification of blood meals in Phlebotomus perniciosus from a focus of human leishmaniasis in Madrid, Spain. Parasitol Res 112:2453-2459

44. Carrillo E, Ahmed S, Goldsmith-Pestana K, Nieto J, Osorio Y, Travi B, Moreno J, McMahon-Pratt D (2007) Immunogenicity of the P-8 amastigote antigen in the experimental model of canine visceral leishmaniasis. Vaccine 25:1534-1543

45. Rogers ME, Sizova OV, Ferguson MA, Nikolaev AV, Bates PA (2006) Synthetic glycovaccine protects against the bite of leishmania-infected sand flies. J Infect Dis 194:512-518

46. Peters NC, Kimblin N, Secundino N, Kamhawi S, Lawyer P, Sacks DL (2009) Vector transmission of Leishmania abrogates vaccine-induced protective immunity. PLoS Pathog 5:e1000484

47. Killick-Kendrick R, Leaney AJ, Ready PD, Molyneux DH (1977) Leishmania in phlebotomid sandflies. IV. The transmission of Leishmania mexicana amazonensis to hamsters by the bite of experimentally infected Lutzomyia longipalpis. Proc R Soc Lond B Biol Sci 196:105-115

48. Beach R, Kiilu G, Hendricks L, Oster C, Leeuwenburg J (1984) Cutaneous leishmaniasis in Kenya: transmission of Leishmania major to man by the bite of a naturally infected Phlebotomus duboscai. Trans R Soc Trop Med Hyg 78:747-751

49. Hanafi HA, el Sawaf BM, Fryauff DJ, Modi GB, Presley SM (1996) Experimental infection and transmission of Leishmania major by laboratoryreared Phlebotomus bergeroti parrot. Am J Trop Med Hyg 54:644-646

50. Chung HL, Feng LC, Feng SL (1951) Observations concerning the successful transmission of kala-azar in North China by the bites of naturally infected Phlebotomus chinensis. Peking Nat Hist Bull 19:302-326

51. Richman DD, Cleveland PH, Oxman MN, Johnson KM (1982) The binding of staphylococcal protein A by the sera of different animal species. J Immunol 128:2300-2305

52. Meleney HE (1925) The Histopathology of Kala-Azar in the Hamster, Monkey, and Man. Am J Pathol 1(147-168):111

53. Silva Junior GB, Barros EJ, Daher Ede F (2014) Kidney involvement in leishmaniasis-a review. Braz J Infect Dis 18:434-440

54. Martis N, Pomares C, Jeandel PY, Lazure T, Marty P, Rosenthal E (2015) Hepatopulmonary syndrome associated with visceral leishmaniasis. Immunol Res 61:169-171

55. Oliveira E, Oshiro ET, Pinto RV, Castro BC, Daniel KB, Oliveira JM, Junior MS, Guimaraes EB, Silva JM, Dorval ME (2011) Presence of amastigotes in the central nervous system of hamsters infected with Leishmania sp. Rev Bras Parasitol Vet 20:97-102

56. Márquez M, Pedregosa JR, López J, Marco-Salazar P, Fondevila D, Pumarola M (2013) Leishmania amastigotes in the central nervous system of a naturally infected dog. J Vet Diagn Invest 25:142-146

57. Quinnell RJ, Courtenay O (2009) Transmission, reservoir hosts and control of zoonotic visceral leishmaniasis. Parasitology 136:1915-1934 
58. Chicharro C, Llanes-Acevedo I, García E, Nieto J, Moreno J, Cruz I (2013) Molecular typing of Leishmania infantum isolates from a leishmaniasis outbreak in Madrid, Spain, 2009-2012. Euro Surveill 18:20545

59. Domínguez-Bernal G, Jiménez M, Molina R, Ordoñez-Gutiérrez L, Martínez-Rodrigo A, Mas A, Cutuli M, Carrión J (2014) Characterisation of the ex vivo virulence of Leishmania infantum isolates from Phlebotomus perniciosus from an outbreak of human leishmaniosis in Madrid. Spain Parasit Vectors 7:499
Submit your next manuscript to BioMed Central and we will help you at every step:

- We accept pre-submission inquiries

- Our selector tool helps you to find the most relevant journal

- We provide round the clock customer support

- Convenient online submission

- Thorough peer review

- Inclusion in PubMed and all major indexing services

- Maximum visibility for your research

Submit your manuscript at www.biomedcentral.com/submit
(O) Biomed Central 